\title{
Blowout of non-premixed turbulent jet flames with coflow under microgravity condition
}

\author{
Qiang Wang ${ }^{\mathrm{a}, \mathrm{b}}$, Longhua Hu ${ }^{\mathrm{b}, *}$, Shaoming Wanga, Shuangfeng Wang ${ }^{\mathrm{c}}$, Suk Ho Chung ${ }^{\mathrm{d}}$, \\ Osamu Fujita ${ }^{e}$ \\ a School of Transportation Engineering, Hefei University of Technology, Hefei, Anhui 230009, China \\ b State Key Laboratory of Fire Science, University of Science and Technology of China, Hefei, Anhui 230026, China \\ ${ }^{c}$ Chinese Academy of Sciences, Institute of Mechanics, Beijing 100190, China \\ ${ }^{d}$ Clean Combustion Research Center, King Abdullah University of Science and Technology (KAUST), Thuwal, Saudi Arabia \\ e Division of Mechanical and Space Engineering, Hokkaido University, Sapporo 060-8628, Japan
}

\section{A R T I C L E I N F O}

Article history:

Received 31 March 2019

Revised 20 June 2019

Accepted 29 August 2019

\section{Keywords:}

Non-premixed turbulent jet flame

Coflow

Blowout limit

Microgravity

Damköhler number

\begin{abstract}
A B S T R A C T
The blowout behavior of non-premixed turbulent coflow jet flames under microgravity environment was studied experimentally by utilizing a $3.6 \mathrm{~s}$ drop tower. Variations of flames leading to liftoff as well as blowout were examined by varying the coflow velocity and compared with those obtained under the normal gravity condition. A modeling work was conducted to incorporate the effects of the gravity (buoyancy) and coflow velocity on blowout behavior. Major findings include: (1) the flame length in microgravity was longer than that in normal gravity and decreased with increasing coflow velocity. The flame in microgravity showed more intense yellow luminosity with larger sooting zone; (2) the flame liftoff height increased with increasing coflow velocity in both gravity levels. The flame base was closer to the burner in microgravity as compared with that in normal gravity; (3) the blowout velocity in microgravity was appreciably larger than that obtained in normal gravity; and (4) a physical model based on Damköhler number was developed by using similarity solutions to characterize the differences in the blowout limits considering both the coflow and gravity (buoyancy) effects. The proposed model can successfully predict the experimental data. This work provided new data and basic scaling analysis for blowout limit of non-premixed turbulent jet flames considering both the coflow and gravity (buoyancy) effects.
\end{abstract}

(c) 2019 The Combustion Institute. Published by Elsevier Inc. All rights reserved.

\section{Introduction}

A blowout limit in non-premixed turbulent jet flames represents a critical maximum jet velocity beyond which a flame cannot be sustained. It is an important parameter in characterizing the flame stabilization, because of its fundamental significance as well as practical application in industrial burner design. This subject has been extensively investigated to understand the physical mechanisms of blowout. Vanquickenborne and van Tiggelen [1] pioneered liftoff and blowout behaviors of non-premixed turbulent jet flames and proposed a premixed flame model, i.e., lifted flame is stabilized when premixed fuel/air flame at the lifted flame base travels against the fuel stream with the same speed as local flow velocity and blowout occurs when the flame base moves downstream into a region where the flame speed can no longer match a local jet velocity. Based on this model, Kalghatgi [2] developed a the-

\footnotetext{
* Corresponding author.

E-mail address: hlh@ustc.edu.cn (L. Hu).
}

ory and successfully quantified blowout limits for various fuels in non-premixed turbulent jet flames in quiescent air. While Broadwell et al. [3] proposed a large-scale mixing model emphasizing the re-entrainment of hot burnt gas into unreacted fuel mixtures for flame stabilization. A blowout criterion based on a Damköhler number (the ratio of turbulent mixing time to chemical reaction time) characterized the blowout behavior. Annushkin and Sverdlov [4] studied experimentally the blowout behavior of hydrogen and various hydrocarbon fuel jets and found a dependence of blowout velocity linearly increasing with nozzle diameter and $\mathrm{Wu}$ et al. [5] investigated the dilution effect.

Chung and co-workers [6-9] studied the stabilization mechanism of laminar flames in a free jet, including liftoff, lifted flames, and blowout. They [9] further extended the liftoff and blowout theory of laminar jet flame to coflow condition by introducing similarity solutions for the velocity and concentration of laminar cold jets. Concerning the effect of coflow on turbulent jet flames, Dahm and Dibble [10], Dahm and Mayman [11], and Feikema et al. [12] investigated the liftoff and blowout limits of turbulent jet flames. 


\begin{tabular}{|c|c|c|c|}
\hline \multicolumn{4}{|c|}{ Nomenclature } \\
\hline$A F$ & \multicolumn{3}{|c|}{ stoichiometric air to fuel mass ratio } \\
\hline$c_{\mathrm{p}}$ & \multicolumn{3}{|c|}{ specific heat at constant pressure $[\mathrm{J} /(\mathrm{kg} \mathrm{K})]$} \\
\hline$d_{\mathrm{A}}$ & \multicolumn{3}{|c|}{ inner diameter of coflow air nozzle $[\mathrm{mm}]$} \\
\hline$d_{\mathrm{F}}$ & \multicolumn{3}{|c|}{ inner diameter of central fuel nozzle [mm] } \\
\hline $\mathrm{Da}$ & \multicolumn{3}{|c|}{ Damköhler number } \\
\hline$g$ & \multicolumn{3}{|l|}{ gravitational acceleration $\left[\mathrm{m} / \mathrm{s}^{2}\right]$} \\
\hline$H_{\mathrm{L}}$ & \multicolumn{3}{|l|}{ liftoff height [m] } \\
\hline$l_{\mathrm{f}}$ & \multicolumn{3}{|l|}{ flame length at blowout [m] } \\
\hline$r_{\mathrm{e}}$ & \multicolumn{3}{|c|}{ nozzle radius $[\mathrm{m}]$} \\
\hline$R_{\mathrm{AF}}$ & \multicolumn{3}{|c|}{ diameter ratio of air to fuel nozzles $\left(d_{\mathrm{A}} / d_{\mathrm{F}}\right)$} \\
\hline $\operatorname{Re}_{\mathrm{F}}$ & \multicolumn{3}{|c|}{ fuel jet Reynolds number } \\
\hline$S_{\mathrm{L}}$ & \multicolumn{3}{|l|}{ laminar burning velocity [m/s] } \\
\hline$T_{\mathrm{f}}$ & \multicolumn{3}{|l|}{ flame temperature $[\mathrm{K}]$} \\
\hline$T_{\mathrm{A}}$ & \multicolumn{3}{|l|}{ ambient temperature [K] } \\
\hline$u$ & \multicolumn{3}{|l|}{ local axial velocity $[\mathrm{m} / \mathrm{s}]$} \\
\hline$U_{\mathrm{A}}$ & \multicolumn{3}{|l|}{ mean coflow velocity at nozzle exit $[\mathrm{m} / \mathrm{s}]$} \\
\hline$U_{\mathrm{B}}$ & \multicolumn{3}{|l|}{ buoyancy induced velocity $[\mathrm{m} / \mathrm{s}]$} \\
\hline$U_{\mathrm{CL}}$ & \multicolumn{3}{|l|}{ centerline velocity $[\mathrm{m} / \mathrm{s}]$} \\
\hline$U_{\tilde{F}}$ & \multicolumn{3}{|l|}{ mean fuel jet velocity at nozzle exit $[\mathrm{m} / \mathrm{s}]$} \\
\hline$\tilde{U}$ & \multicolumn{3}{|l|}{ non-dimensional velocity } \\
\hline$U^{*}$ & \multicolumn{3}{|l|}{ velocity ratio of air and fuel $\left(U_{\mathrm{A}} / U_{\mathrm{F}}\right)$} \\
\hline$x$ & \multicolumn{3}{|l|}{ axial coordinate $[\mathrm{m}]$} \\
\hline \multicolumn{4}{|c|}{ Greek symbols } \\
\hline$\alpha$ & \multicolumn{3}{|l|}{ thermal diffusivity $\left[\mathrm{m}^{2} / \mathrm{s}\right]$} \\
\hline$\beta$ & $\begin{array}{l}\text { non-dimensional parameter in } \\
\beta=\left(\rho_{\mathrm{F}} / \rho_{\mathrm{A}}\right)\left(d_{\mathrm{F}} / d_{\mathrm{A}}\right)^{2}\end{array}$ & & {$[12]$,} \\
\hline$\delta$ & local flame diameter [m] & & \\
\hline$\eta$ & $\begin{array}{l}\text { non-dimensional parameter in } \\
\eta=1 /\left[1-\left(d_{\mathrm{F}} / d_{\mathrm{A}}\right)^{2}\right]\end{array}$ & Ref. & [12], \\
\hline$\rho$ & density $\left[\mathrm{kg} / \mathrm{m}^{3}\right]$ & & \\
\hline$\rho_{\mathrm{F}}$ & fuel density $\left[\mathrm{kg} / \mathrm{m}^{3}\right]$ & & \\
\hline$\rho_{\mathrm{A}}$ & coflow air density $\left[\mathrm{kg} / \mathrm{m}^{3}\right]$ & & \\
\hline$\tau_{\mathrm{c}}$ & characteristic reaction time $[\mathrm{s}]$ & & \\
\hline$\tau_{\mathrm{m}}$ & characteristic mixing time [s] & & \\
\hline$\lambda$ & thermal conductivity [W/(m K)] & & \\
\hline$\zeta$ & empirical constant & & \\
\hline$\xi$ & $\begin{array}{l}\text { non-dimensional parameter in } \\
\xi=\left[\left(S_{\mathrm{L}}^{2} / \alpha\right)(1+A F)^{2} / 4.8\right]^{2 / 3}\end{array}$ & Ref. & {$[12]$,} \\
\hline$v$ & kinematic viscosity $\left[\mathrm{m}^{2} / \mathrm{s}\right]$ & & \\
\hline Subs & & & \\
\hline A & air & & \\
\hline cal & calculated & & \\
\hline eff & effective & & \\
\hline f & flame & & \\
\hline $\mathrm{F}$ & fuel & & \\
\hline
\end{tabular}

The Dahm-Mayman model [11,12] was proposed by taking the fuel jet and coflow as a hypothetical single jet source. Muniz and Mungal [13] and Brown et al. [14] following the theory proposed by Vanquickenborne and van Tiggelen [1], analyzed the balance between local flow velocity and turbulent burning velocity of coflow jet flames to explain the flame blowout. These studies, however, were mainly conducted under the normal gravity condition.

Under the normal gravity condition, turbulent jet flames are influenced by the presence of buoyant natural convection. An example is buoyancy-induced instabilities often encounters in jet flames, as manifested by a flickering behavior of laminar jet flames, where the buoyancy effect is sufficiently strong to interfere with jet flow-field. Nevertheless, there is still very limited works reported on blowout limit of turbulent jet flames under a microgravity condition. In recent years, several works $[15,14-20]$ indicated that the flame behavior in microgravity significantly differs from that in normal gravity. Lock et al. [15] compared the liftoff characteristics of laminar partially-premixed flames (PPFs) with coflow under normal- and micro-gravity conditions, and found that a lifted flame is stabilized closer to the burner under the $\mu$-g condition. Also, the blowout velocity of a non-premixed jet flame without having a coflow was substantially higher in microgravity than that in normal gravity [16]. Brooker et al. [17] confirmed that the blowout velocity of laminar jet flame with coflow is much higher in microgravity than that in normal gravity. However, there is a lack of studies on the blowout limit of turbulent non-premixed jet flames with coflow in microgravity and a quantification of the gravity (buoyancy) effect has not been reported yet. Note that a systematic and accurate data free from a gravity (buoyancy) effect is crucial to test various theoretical models for blowout of lifted flames and a coflow configuration is suitable for comparison with numerical simulations considering the specification of boundary conditions.

In the present study, a series of experiments was carried out by utilizing a drop tower to study the blowout behavior of coflow non-premixed turbulent jet flames in microgravity $(\mu-\mathrm{g})$ and the data were compared with those obtained in normal gravity $(1-\mathrm{g})$. A theoretical model was developed to predict the blowout limit through which a unified quantification of blowout velocities is achieved by considering both the effects of coflow and gravity (buoyancy).

\section{Experiment}

The experiments were conducted utilizing the drop tower [18] in National Microgravity Laboratory of China (NMLC), which has an effective height of $83 \mathrm{~m}$ providing a microgravity environment with the level of $10^{-3}-10^{-4} \mathrm{~g}$ for $3.6 \mathrm{~s}$ duration. A schematic of the experimental apparatus is shown in Fig. 1, mainly consists of a coflow burner, a flow control system, and a measurement setup. The coflow burner has a fuel nozzle with an inner diameter of $d_{\mathrm{F}}=1 \mathrm{~mm}$ and a length of $95 \mathrm{~mm}$ to ensure a fully developed pipe flow condition, which is surrounded by a coflow air nozzle with the diameter of $d_{A}=43 \mathrm{~mm}$. The fuel used was commercially-pure grade propane and the oxidizer was air, which passed through beads and a honeycomb for uniform outlet velocity. The flow rates of fuel and air were monitored by mass flow controllers. The burner and flow control system were packed in an enclosed capsule.

Various electronic controllers including programmable logic controllers automated the sequence of experiment. A flame was firstly ignited with a spark plug installed on an electronic stepping motor $10 \mathrm{~s}$ before the capsule was released. After ignition, the motor rotated the spark plug away not to disturb the flow field. During the descending of the capsule, the coflow air velocity was increased continuously for a blowout to occur, as similar to that did in [19]. The reason for the control of the coflow air velocity is that a blowout is more sensitive to coflow velocity especially at large fuel jet velocities. Note that the time delay from the flow rate control system was calibrated as was done in [19] in determining real-time flow rate.

A CCD digital camera (30 fps) was used to record the flame images. Corresponding experiments in normal gravity were conducted with the same capsule on the ground. The experimental conditions are summarized in Table 1 in terms of the fuel jet velocity $U_{\mathrm{F}}$, corresponding Reynolds number $R e_{\mathrm{F}}=U_{\mathrm{F}} d_{\mathrm{F}} / \nu$, and coflow air velocity $U_{\mathrm{A}}$, where $v$ is the kinematic viscosity of fuel. Three experiments were conducted for a specified condition and the average value is presented. The flame length $L_{\mathrm{f}}$ was measured from the nozzle orifice to luminous flame tip from recorded flame images. The liftoff height $H_{\mathrm{L}}$ was measured from the nozzle orifice to a luminous flame base. Every image captured during the drop in 


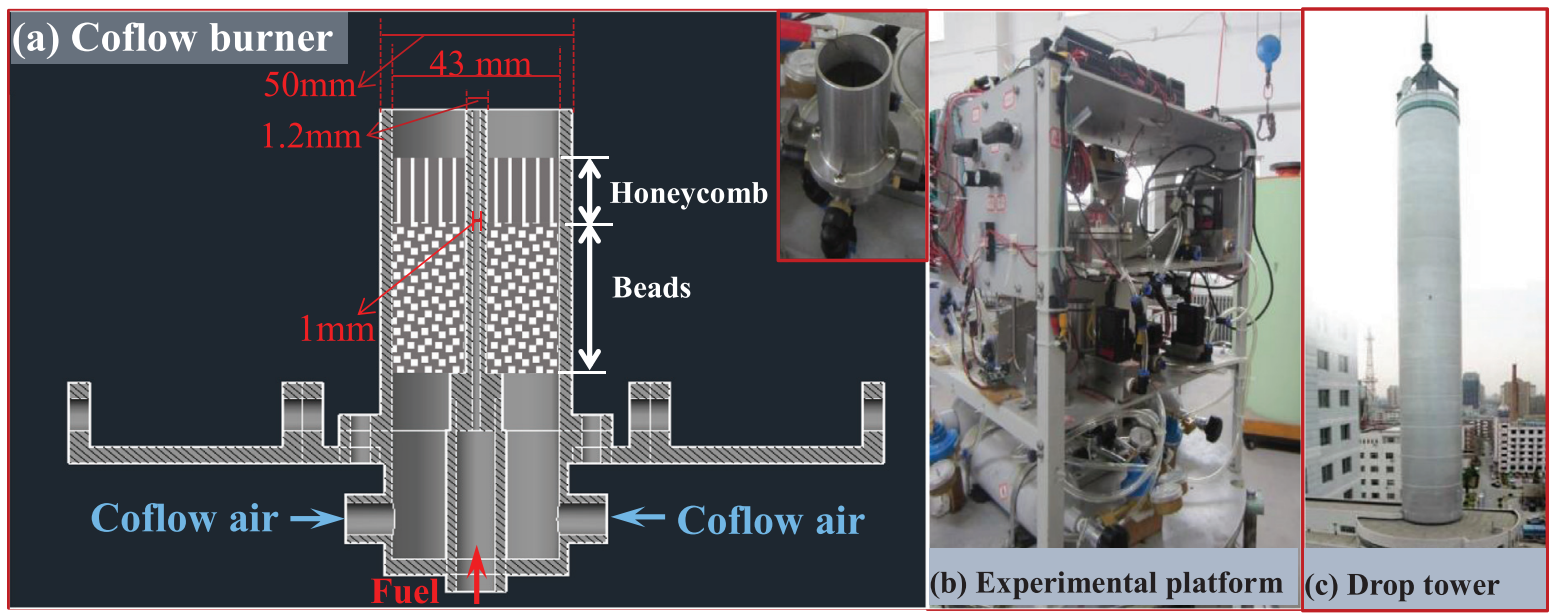

Fig. 1. Experimental setup (a) coflow burner; (b) experimental platform; and (c) drop tower.

Table 1

Summary of experimental conditions.

\begin{tabular}{|c|c|c|c|c|c|c|c|}
\hline \multicolumn{4}{|l|}{ Gravity level: 1-g } & \multicolumn{4}{|c|}{ Gravity level: $\mu$-g } \\
\hline $\begin{array}{l}\text { Fuel velocity } U_{\mathrm{F}} \\
{[\mathrm{m} / \mathrm{s}]}\end{array}$ & $\begin{array}{l}\text { Coflow air velocity } \\
U_{\mathrm{A}}[\mathrm{m} / \mathrm{s})\end{array}$ & $\operatorname{Re}_{\mathrm{F}}$ & $\begin{array}{l}\text { Blow out } \\
(\mathrm{Y} / \mathrm{N})\end{array}$ & $\begin{array}{l}\text { Fuel velocity } \\
U_{\mathrm{F}}[\mathrm{m} / \mathrm{s}]\end{array}$ & $\begin{array}{l}\text { Coflow air velocity } \\
U_{\mathrm{A}}[\mathrm{m} / \mathrm{s}]\end{array}$ & $\operatorname{Re}_{\mathrm{F}}$ & $\begin{array}{l}\text { Blow out } \\
(\mathrm{Y} / \mathrm{N})\end{array}$ \\
\hline 6.37 & 0.50 & 1649.29 & $\mathrm{~N}$ & 6.37 & 0.50 & 1649.29 & $\mathrm{~N}$ \\
\hline 6.37 & 0.56 & 1649.29 & $\mathrm{~N}$ & 6.37 & 0.56 & 1649.29 & $\mathrm{~N}$ \\
\hline 6.37 & 0.62 & 1649.29 & $\mathrm{~N}$ & 6.37 & 0.62 & 1649.29 & $\mathrm{~N}$ \\
\hline 6.37 & 0.73 & 1649.29 & $\mathrm{Y}$ & 6.37 & 0.90 & 1649.29 & $\mathrm{Y}$ \\
\hline 8.49 & 0.63 & 2198.19 & $\mathrm{Y}$ & 8.49 & 0.84 & 2198.19 & $\mathrm{Y}$ \\
\hline 10.62 & 0.50 & 2749.67 & $\mathrm{~N}$ & 10.62 & 0.50 & 2749.67 & $\mathrm{~N}$ \\
\hline 10.62 & 0.58 & 2749.67 & $\mathrm{Y}$ & 10.62 & 0.73 & 2749.67 & $\mathrm{Y}$ \\
\hline 12.74 & 0.48 & 3298.57 & $\mathrm{Y}$ & 12.74 & 0.61 & 3298.57 & $\mathrm{Y}$ \\
\hline 16.99 & 0.45 & 4398.96 & $\mathrm{Y}$ & 16.99 & 0.51 & 4398.96 & $\mathrm{Y}$ \\
\hline 19.11 & 0.35 & 4947.86 & $\mathrm{Y}$ & & & & \\
\hline 21.23 & 0.28 & 5496.76 & $\mathrm{Y}$ & & & & \\
\hline 23.36 & 0.20 & 6048.25 & $\mathrm{Y}$ & & & & \\
\hline 25.48 & 0.20 & 6597.15 & $\mathrm{Y}$ & & & & \\
\hline 27.60 & 0.00 & 7146.05 & $\mathrm{Y}$ & & & & \\
\hline
\end{tabular}

microgravity and corresponding blowout process in normal gravity was processed with a Matlab program. For each image, a cluster analysis method based on OTSU algorithm [20], as applied in $[21,22]$ to ensure local maximum likelihood contrast between the flame and background, was used to demarcate the flame edge that separates the flame from the background. Thus, the flame tip and the lifted flame base could be identified. A typical output image of the program is presented in Fig. 2 .

\section{Results and discussion}

\subsection{Flame evolution}

Figure 3 shows a typical behavior of flame length, which is the vertical distance from the nozzle orifice to the flame tip, during the transition from normal gravity $(1-\mathrm{g})$ to microgravity $(\mu-\mathrm{g})$ as the capsule started to fall for $U_{\mathrm{F}}=6.37 \mathrm{~m} / \mathrm{s}$ and $U_{\mathrm{A}}=0.62 \mathrm{~m} / \mathrm{s}$. The variation of gravity level is also plotted. Before releasing the drop capsule, the ignited coflow jet flame is maintained steadily for about $10 \mathrm{~s}$ to ensure the flame reaching a quasi-steady condition. During this period, the flame length shows typical fluctuations of a turbulent jet flame. As the capsule is released, the gravity level changes from $1 \mathrm{~g}$ to $10^{-3}-10^{-4} \mathrm{~g}$ within, say $0.2 \mathrm{~s}$. Then, the flame length responds to the change in the gravity level within, say $0.4 \mathrm{~s}$. Note that the flame length rapidly increases and then gets re-stabilized as a quasi-stable flame in microgravity.

The flame length in microgravity is larger than that in normal gravity. This can be attributed to the buoyancy effect, as

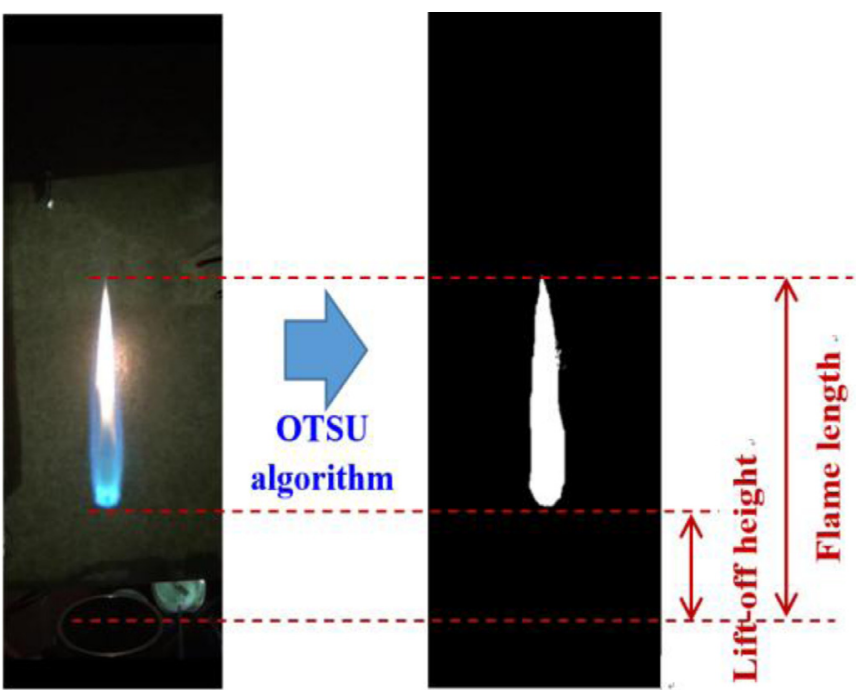

Fig. 2. Identification of flame tip and lifted flame base with a Matlab program based on OTSU algorithm [20], as applied in [21,22].

was pointed out in previous works [15,23-25]. In normal gravity, buoyancy-induced air entrainment plays as an important role, especially in the turbulent diffusion processes as the gas velocity is increased by buoyancy. Since the fuel is consumed stoichiometrically with air, as the entrained air increases, the flame length de- 


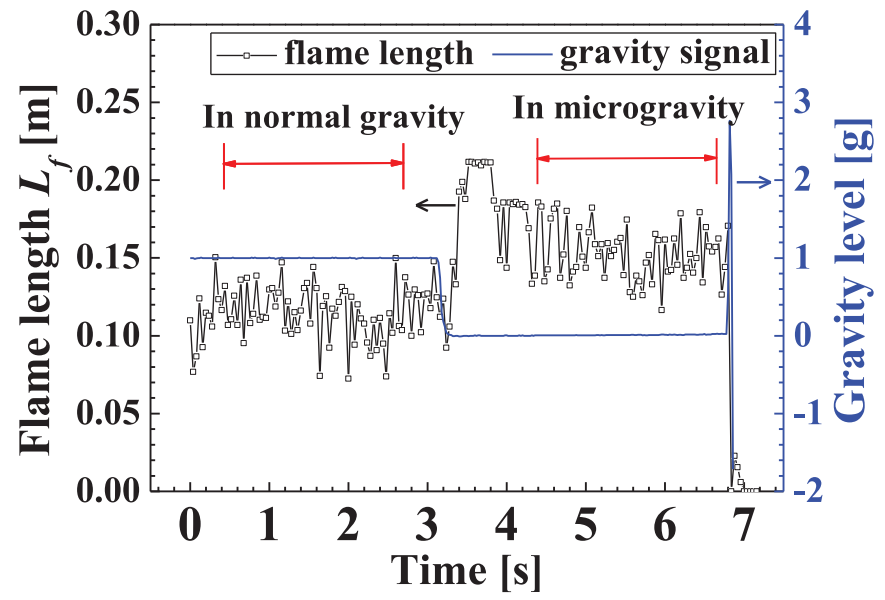

Fig. 3. Variation of flame length during transition from normal- to micro-gravities for $U_{\mathrm{F}}=6.37 \mathrm{~m} / \mathrm{s}$ and $U_{\mathrm{A}}=0.62 \mathrm{~m} / \mathrm{s}$ along with gravity level.

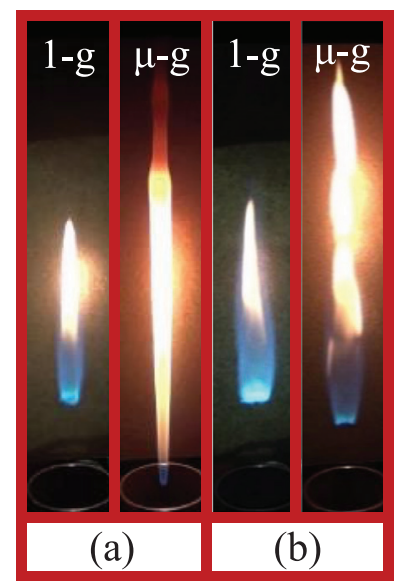

Fig. 4. Flames images in normal- and micro-gravities for (a) $\left(U_{\mathrm{F}}[\mathrm{m} / \mathrm{s}], U_{\mathrm{A}}\right.$ $[\mathrm{m} / \mathrm{s}])=(6.37,0.5)$ and $(\mathrm{b})(10.6,0.5)$.

creases. In microgravity, the lack of buoyant convection makes the flame to be longer. This was confirmed for both laminar and turbulent jet flames [26]. Such observation is in contrast to a candle flame, which shows an opposite trend, by decreasing its length as the gravity level is reduced [27]. For such a candle flame in normal gravity, since the fuel velocity is typically very low, the buoyant convection increases the fuel velocity significantly centrally, so that the candle flame length shows to be longer in normal gravity.

Figure 4 shows the flame images, typically taken when the flame reached a quasi-stable state for two fuel jet velocities (6.37 and $10.62 \mathrm{~m} / \mathrm{s})$ at a fixed coflow velocity $(0.5 \mathrm{~m} / \mathrm{s})$ in normal- and micro-gravities. The result clearly indicates an appreciable increase in the flame length under the microgravity condition. Note that the flame under the microgravity condition shows much more intense yellow luminosity with larger yellow luminous zone, which is consistent with the previously observed sooting tendency with gravity $[24,25]$. Moreover, smoke particles are observed in the flame under the $\mu$-g condition with soot emitted from the flame tip, also indicating that soot production is enhanced in microgravity.

Here, it is worthwhile to discuss the gravity effect on soot yield for a jet flame, where the initial momentum of gaseous fuel plays an important role. Overall soot production in a flame is determined by the interplay between soot formation and oxidation. Under a microgravity condition, when the fuel momentum is quite small, where soot formation is controlling, the jet flame resem- bles the behavior of candle flame [28,29]. In this condition, oxygen is mainly transported by diffusion. Meanwhile, due to the absence of natural convection, combustion products can mainly be transported away by diffusion, further hindering the transport of oxygen. These factors result in a weaker mixing of fuel with air, and make the combustion reaction less vigorous and flame temperature lower than that in normal gravity [30]. Thus, less soot is produced. Moreover, spatially distributed character of soot growth path [31] in microgravity also makes soot to be harder to be accumulated or formed. However, when the fuel momentum is considerable, the flame sizes in both gravities are appreciably enlarged and soot oxidation is controlling. In normal gravity, the buoyancy induced air entrainment increases the air (oxygen) supply into the flame, which enhances the soot oxidation and leads to an overall lower soot production, which is similar to the observation in the present study for turbulent flames. Note also that the increased liftoff height in normal gravity as compared with that in microgravity reduces soot production by the partial premixing of fuel and air inside the flame zone.

For $U_{\mathrm{F}}=6.37 \mathrm{~m} / \mathrm{s}$, the flame image under normal gravity $(1-\mathrm{g})$ shows a lifted flame, while under microgravity $(\mu-\mathrm{g})$ the flame is nozzle-attached. For $U_{\mathrm{F}}=10.6 \mathrm{~m} / \mathrm{s}$, both flames are lifted, however, having a relatively smaller liftoff height in microgravity $(\mu-\mathrm{g})$. This indicates that the buoyancy-induced convection not only influences the flame shape, but also impacts on the flame stabilization behavior, which is discussed in the following.

\subsection{Flame length, liftoff height, and blowout}

Figure 5 shows the variations of flame length and liftoff height at quasi-stable conditions in both normal- and micro-gravities. As the coflow air velocity increases $(a-c)$, it was observed that: (1) both the flame length and its difference between the normal- and micro-gravities decrease; and (2) the liftoff height somewhat increases in both gravity levels, and is stabilized closer to the nozzle in microgravity as compared with that in normal gravity.

A lifted flame is stabilized by the competition between flame speed and local flow velocity near the flame edge. Although the entrainment flow induced by buoyancy can lead to better mixing, decreasing the mixture fraction gradient leads to the increase in edge flame speed (say in the order of $\sim 10^{0-1} \mathrm{~cm} / \mathrm{s}$ ) [32,33]. While the local flow velocity is much more accelerated by buoyancy (say in the order of $\sim 10^{1-2} \mathrm{~cm} / \mathrm{s}$ ) [34,35], about one order of magnitude higher than the variation in the flame edge speed. Thus, the liftoff height in normal gravity is higher than that in microgravity, which was also reported by Kim et al. [36]. With regard to the flame length, buoyant air entrainment modifies the reaction zone by enhancing the mixing and thereby leads to a smaller flame length and less luminosity in normal gravity than that in microgravity. As to the effect of coflow, the forced convection is enhanced with higher coflow air velocity. This also promotes the air mixing and mitigates the relative importance of buoyancy effect [37], resulting in the decrease in the flame length and the difference in the flame lengths between the normal- and micro-gravities. However, even though the difference of the flame length in Fig. 5(a)-(c) is getting smaller with increasing coflow velocity, the visible flame length measured from the flame base to the flame tip is still obviously different in normal gravity from that in microgravity. This indicates the buoyancy effect is not negligible.

Figure 6 shows typical images of non-premixed turbulent jet flames that exhibit blowout processes (at a fixed fuel flow velocity of $8.49 \mathrm{~m} / \mathrm{s}$ ), extinguishing the flame by continuous increase in the coflow air velocity in both normal- and micro-gravities. The flames with small $U_{\mathrm{A}}$ exhibit bright blue edges presumably having a stoichiometric tribrachial edge flame structure with premixed flame wings followed by a less luminous trailing diffusion flames 


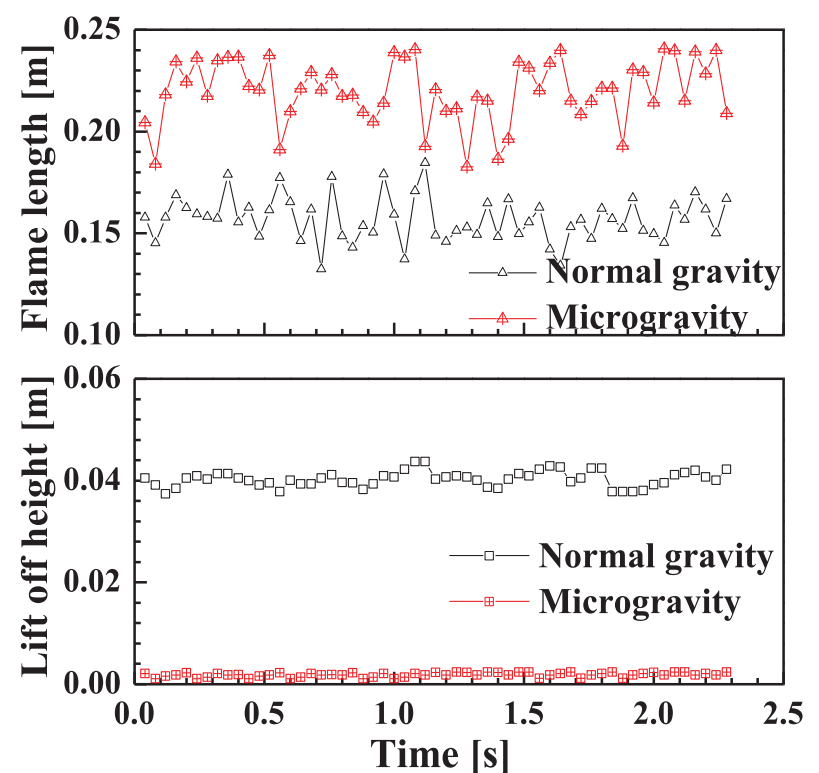

(a) $\left(U_{\mathrm{F}}, U_{\mathrm{A}}\right)=(6.37,0.5 \mathrm{~m} / \mathrm{s})$

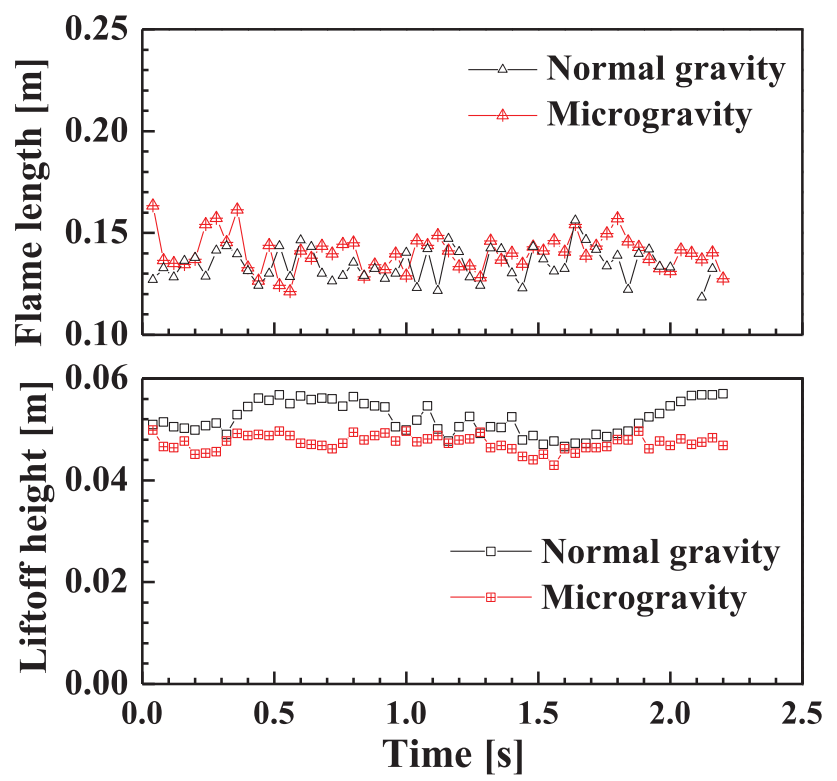

(c) $\left(U_{\mathrm{F}}, U_{\mathrm{A}}\right)=(6.37,0.62 \mathrm{~m} / \mathrm{s})$
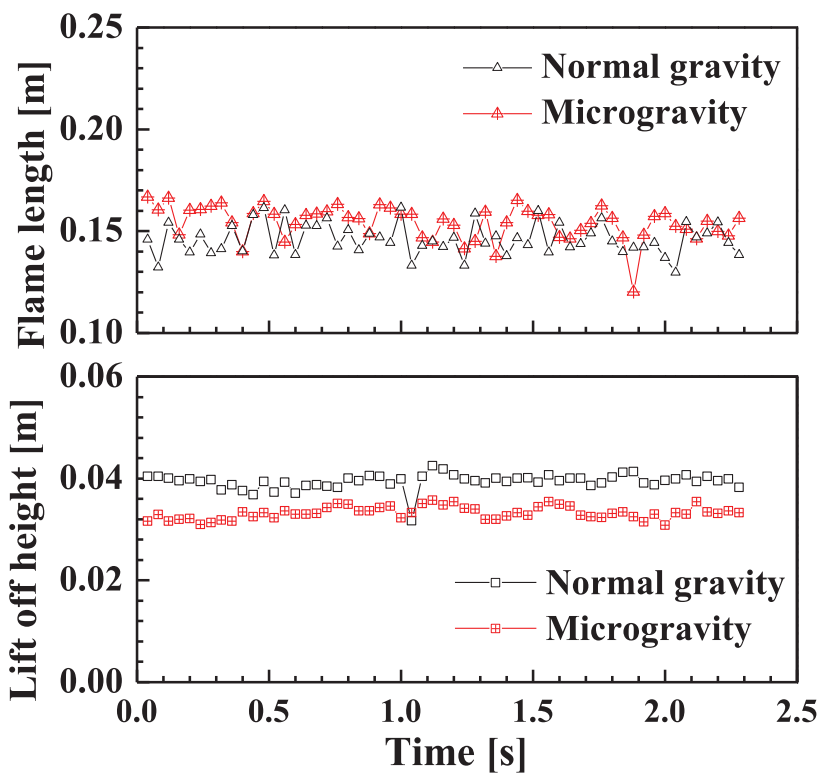

(b) $\left(U_{\mathrm{F}}, U_{\mathrm{A}}\right)=(6.37,0.56 \mathrm{~m} / \mathrm{s})$
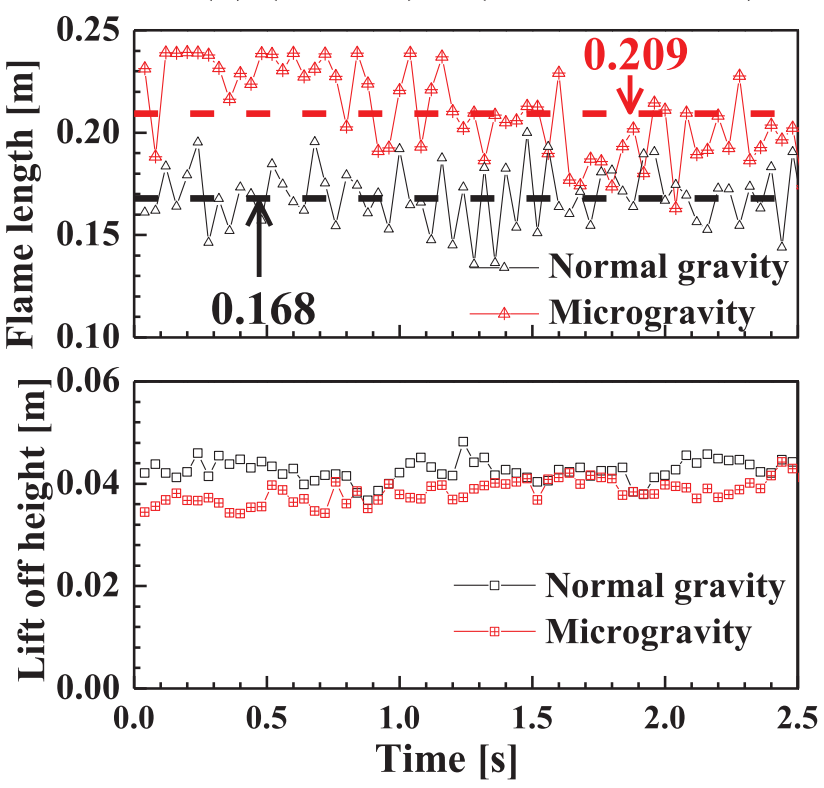

(d) $\left(U_{\mathrm{F}}, U_{\mathrm{A}}\right)=(10.62,0.5 \mathrm{~m} / \mathrm{s})$

Fig. 5. Variations of flame length and liftoff height at various fuel jet and air coflow velocities.

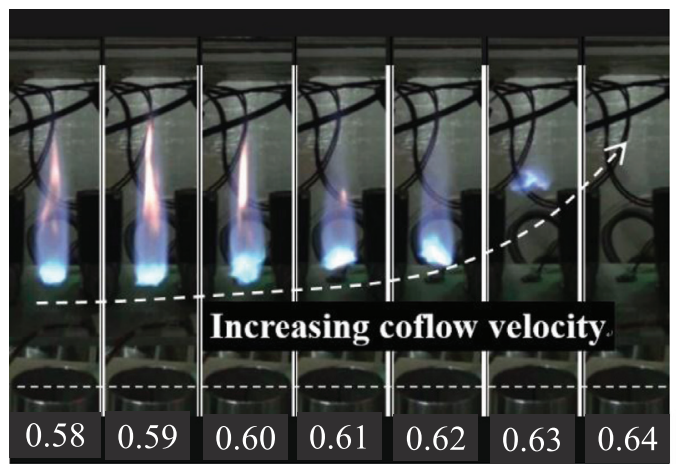

(a) Normal gravity

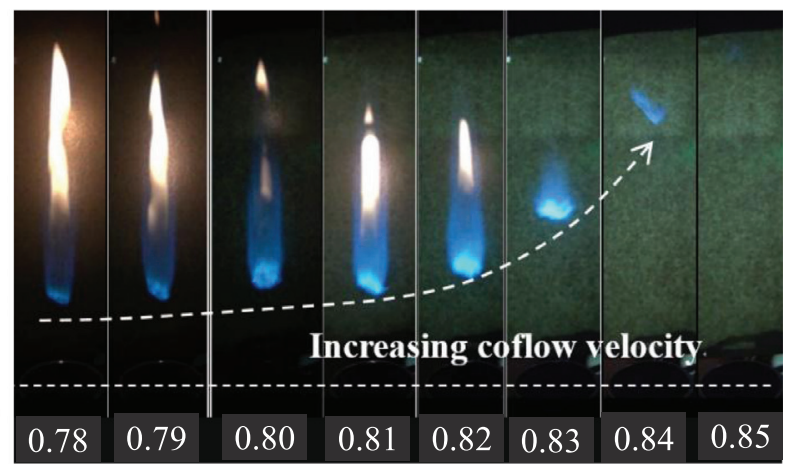

(b) Microgravity

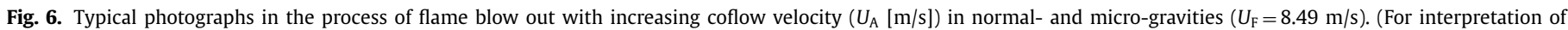
the references to color in this figure, the reader is referred to the web version of this article.) 


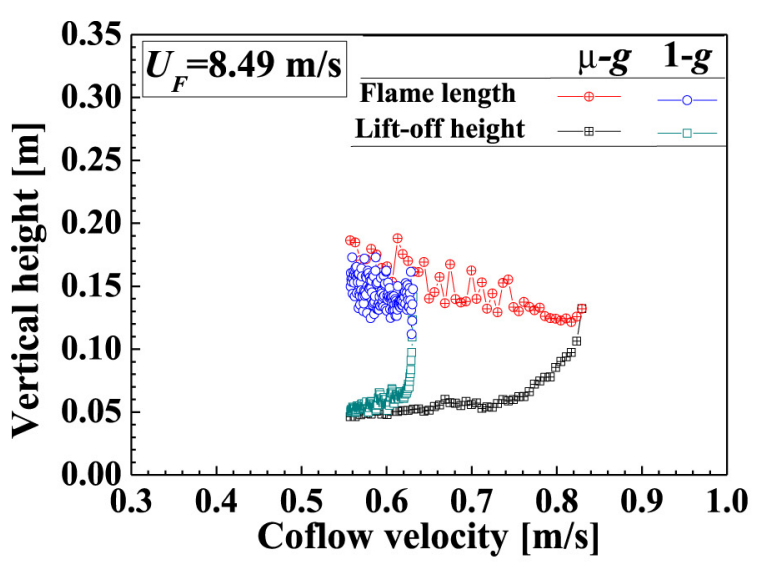

(a)

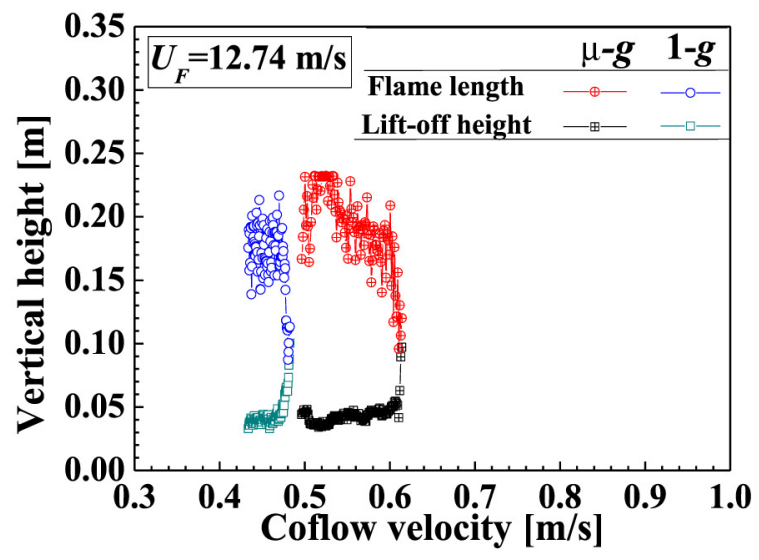

(c)

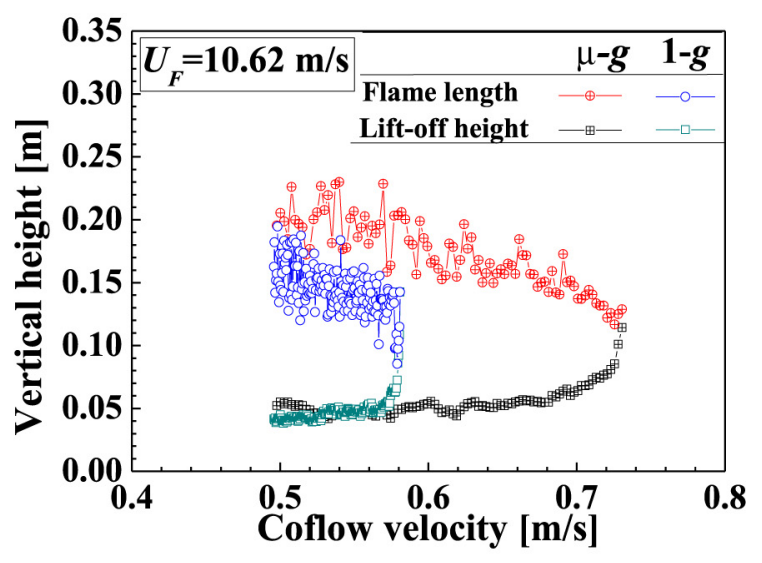

(b)

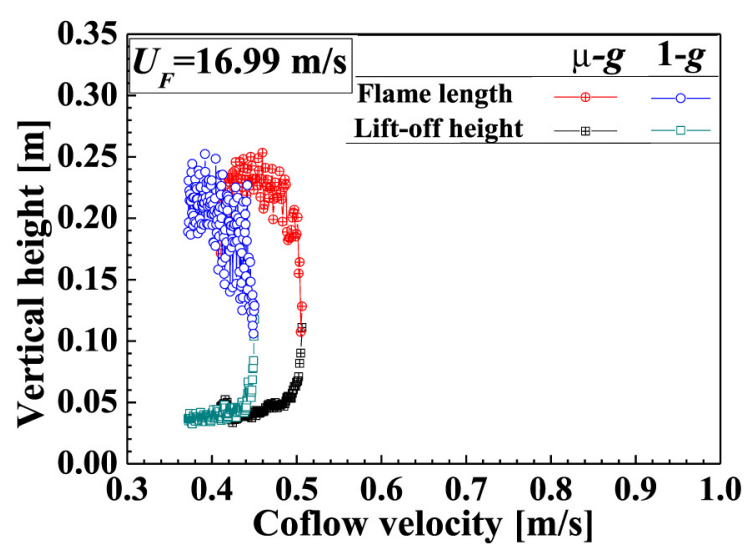

(d)

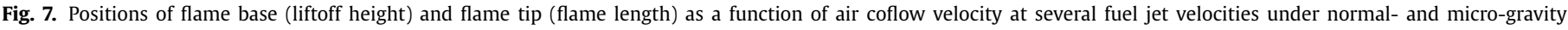
conditions.

$[7,8]$. And then significantly brighter yellow luminous flames (indicating more soot production) appear in the fuel region of the flame envelope, especially in microgravity. As the coflow velocity is gradually increased, the flame base migrates downstream and the flame length decreases. The yellow luminous region disappears due to insufficient time for soot growth and partial premixing. At excessively large $U_{\mathrm{A}}$, a blowout occurs. Note that during the blowout process (last photos), a bright leading edge disappears, implying that the flame base no longer maintains a stoichiometry.

Figure 7 shows the variations in the flame length and liftoff height as a function of coflow air velocity at several fuel jet velocities. As the coflow air velocity increases, the flame length decreases and the liftoff height increases. In the preliminary experiments, the instantaneous flame length close to $U_{\mathrm{A}}=0.5 \mathrm{~m} / \mathrm{s}$ in Fig. 7(b) is consistent with the averaged flame length in Fig. 5(d), confirming that the flame length obtained during the transient coflow velocity condition is nearly identical to that obtained with a fixed coflow velocity in a steady-state condition. As the coflow velocity becomes excessive, the flame length and liftoff height vary rapidly and become merging together, an indication of flame blowout. The flame tip (flame length) and flame base (liftoff height) are observed to exhibit the similar characteristics as discussed above. The most important result is that the critical coflow velocity at blowout for a specified fuel velocity is significantly larger in microgravity than that in normal gravity.

The experimental observations reveal that the effect of coflow on the flame structure and blowout would be significantly modi- fied by gravity. The flame base was closer to the burner under the microgravity as compared with that in normal gravity. Besides, the blowout velocity in microgravity was appreciably larger than that obtained in normal gravity.

\subsection{Blowout behavior}

The experimental data of the blowout limit of fuel jet velocity $U_{\mathrm{F}}$ by varying the coflow velocity $U_{\mathrm{A}}$ is shown in Fig. 8. The result clearly demonstrates that the fuel jet velocity at the blowout limit decreases with the coflow velocity in both normal- and microgravity conditions. Note that the critical fuel jet velocity at blowout in microgravity is appreciably higher than that in normal gravity. This result is consistent with that of Brooker et al. [17], for the case of nozzle-attached laminar diluted methane flames $\left(\operatorname{Re}_{\mathrm{F}} \leq 2000\right)$.

The prediction of Dahm-Mayman model [11], which was further simplified by Feikema et al. [12], is also presented in Fig. 8. The model was proposed on the assumption of equivalent source, which has physical meaning of the conceptual equivalent source that would flow in the same quantity as the actual source, such as mass flux and momentum flux. The critical conditions for blowout was expressed in terms of the parameters of $\xi=\left[\left(S_{\mathrm{L}}^{2} / \alpha\right)(1+A F)^{2} / 4.8\right]^{2 / 3}, \quad \beta=\left(\rho_{\mathrm{F}} / \rho_{\mathrm{A}}\right)\left(d_{\mathrm{F}} / d_{\mathrm{A}}\right)^{2}$, and $\eta=1 /\left[1-\left(d_{\mathrm{F}} / d_{\mathrm{A}}\right)^{2}\right]$ as $U_{\mathrm{A}}^{2}=\xi \beta^{4 / 3} \eta d_{\mathrm{A}}{ }^{2 / 3} U_{\mathrm{F}}{ }^{4 / 3}-\beta \eta U_{\mathrm{F}}^{2}$, where $\alpha$ is the thermal diffusivity $\left(\alpha=\lambda / \rho c_{\mathrm{p}}\right.$, with $\lambda$ the thermal conductivity, $\rho$ is the density, and $c_{\mathrm{p}}$ is the specific heat at constant pressure) and $S_{\mathrm{L}}$ is the laminar burning velocity. The result marked as 


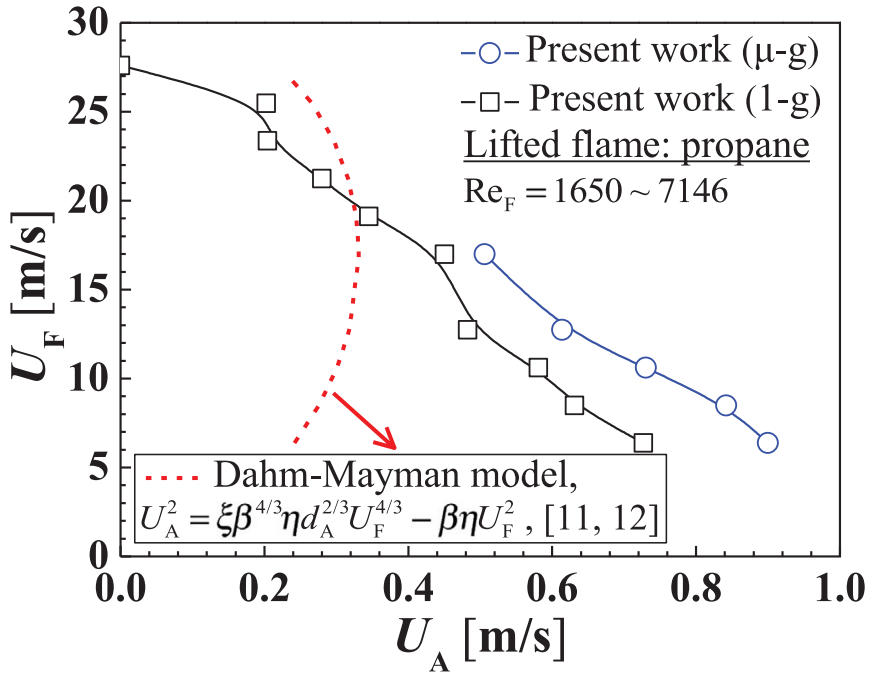

Fig. 8. Fuel jet velocity at blowout as a function of coflow air velocity for lifted turbulent jet flames $\left(\operatorname{Re}_{\mathrm{F}}=1650-7140\right)$. The result from Dahm-Mayman model $[11,12]$ is shown as the red dotted line in terms of parameters $\xi, \beta$, and $\eta$ defined in Refs. $[11,12]$, showing significant deviation from the present results. (For interpretation of the references to color in this figure legend, the reader is referred to the web version of this article.)

the red dotted line exhibits a non-linear behavior, which is qualitatively different from the present experimental data. This can be explained as follows. It has been shown that a confinement in the air side has a significant effect on liftoff height and blowout behaviors in turbulent non-premixed jet flames [38]. Note that in [11,12], the diameter of coflow nozzle is comparable to the diameter of fuel nozzle (the ratio $R_{\mathrm{AF}}=d_{\mathrm{A}} / d_{\mathrm{F}}$ is in the range of 2-2.3 in [11] and 6.54 in [12]). In such cases, the blowout limits of two configurations (inner fuel jet with outer coflow air or inner air jet with outer coflow fuel), for which reversing the fuel and coflow streams produces the same equivalent source representation in the far field, were quite the same. Thus, the fuel jet with air jet for both coflow configurations could be taken as an equivalent source, which is a conceptual equivalent source with the total mass flux $m_{0}$ and total momentum flux $J_{0}$ of both air and fuel, in the far-field in the model.

However, when the nozzle diameter of coflow is much larger than the fuel nozzle diameter (in the present work, $R_{\mathrm{AF}}=d_{\mathrm{A}} / d_{\mathrm{F}}=43$ ), the fuel and air streams cannot be simply taken as an equivalent source, as most of the coflow cannot be entrained into the fuel jet. Thus, the flow-field may be considered as a fuel jet surrounded by a coflow stream with a reasonably infinite diameter. These differences in the present experimental condition may lead to the significant deviation from the prediction based on the Dahm-Mayman model. In the following, we present a detailed discussion on predicting the present results, considering both the coflow and gravity (buoyancy) effects.

\subsection{Modeling of blowout}

A blowout behavior can be viewed at a condition when a lifted flame base cannot sustain an imposed strain rate, or an extinction by an excessive strain rate. This can be expressed in terms of the Damköhler number, Da, defined as the ratio between the characteristic mixing time, $\tau_{\mathrm{m}}$, and the characteristic reaction time, $\tau_{\mathrm{c}}$, similar to the one proposed by Broadwell et al. [3]. The mixing time can be defined as $\tau_{m} \sim \delta / u$, where $\delta$ is the local diameter of jet and $u$ is the local axial velocity. This can be attributed to the molecular mixing [3], since the entrained air and the jet fluid intertwine throughout the jet by large scale where inviscid motions

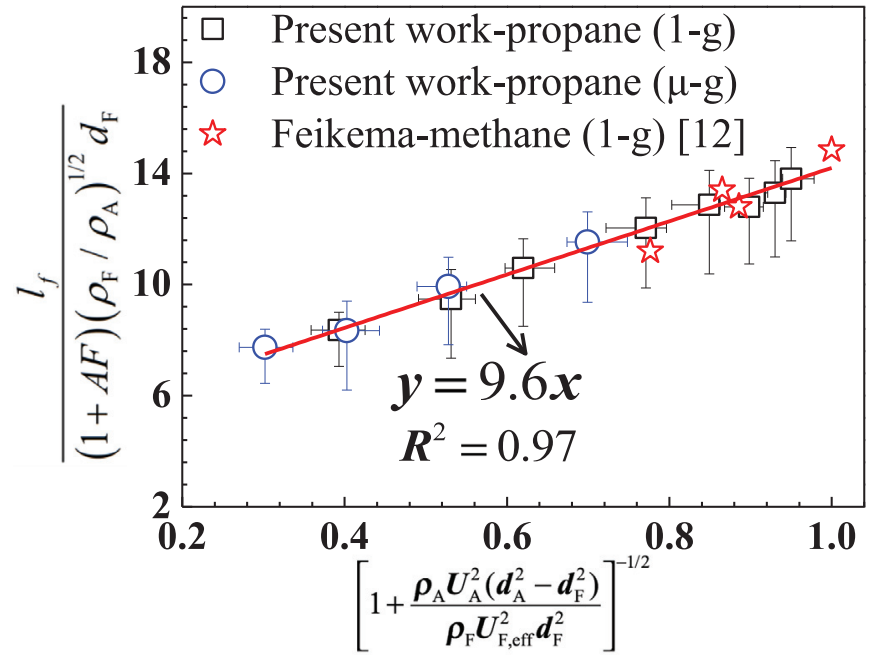

Fig. 9. Correlation of the critical flame length (axial location) at blowout in both normal gravity and microgravity.

scale with the local jet diameter. A Kolmogorov-like cascade begins from this initial state and after a time, $\tau_{m} \sim \delta / u$. The characteristic reaction time can be defined as $\tau_{c} \sim \alpha / S_{L}^{2}$. Then, the Damköhler number becomes:

$\mathrm{Da} \equiv \frac{\tau_{m}}{\tau_{c}} \sim \frac{\delta / u}{\alpha / S_{L}^{2}}$

Based on previous works [39-41], the local diameter of coflow jet can be expressed as:

$\delta=C_{1} l_{f}=\frac{C_{1} C_{2}(1+A F)\left(\rho_{\mathrm{F}} / \rho_{\mathrm{A}}\right)^{1 / 2} d_{\mathrm{F}}}{\left[1+\frac{\rho_{\mathrm{A}} U_{\mathrm{A}}^{2}\left(d_{\mathrm{A}}^{2}-d_{\mathrm{F}}^{2}\right)}{\rho_{\mathrm{F}} U_{\mathrm{F}}^{2} d_{\mathrm{F}}^{2}}\right]^{1 / 2}}$

where $A F$ is the stoichiometric air to fuel mass ratio, $\rho_{\mathrm{F}}$ and $\rho_{\mathrm{A}}$ are the fuel and coflow air densities, respectively, $C_{1}$ is the constant (0.182) determined by the streamwise velocity half-width [39], $C_{2}$ is the empirical constant based on the correlations of critical flame length at blowout in microgravity and normal gravity as will be shown later in Fig. 9.

For a turbulent free jet, the solution for the centerline velocity $U_{\mathrm{CL}}$ [39] is:

$\frac{U_{\mathrm{CL}}(x)}{U_{\mathrm{F}}} \sim\left(\frac{\rho_{\mathrm{F}}}{\rho_{\mathrm{A}}}\right)^{1 / 2} \frac{r_{\mathrm{e}}}{x}$

where $x$ is the axial coordinate and $r_{\mathrm{e}}$ is the nozzle radius. Previously, Lee et al. [9] proposed a similarity solution for the velocity of laminar jet with coflow with the scaling of $\left(U_{\mathrm{CL}}(x)-U_{\mathrm{A}}\right) /\left(U_{\mathrm{F}}-U_{\mathrm{A}}\right)$. In a similar manner, the centerline velocity of turbulent jet with a coflow can be defined as [39]:

$\frac{U_{\mathrm{CL}}(x)-U_{\mathrm{A}}}{U_{\mathrm{F}}-U_{\mathrm{A}}}=C_{3}\left(\frac{\rho_{\mathrm{F}}}{\rho_{\mathrm{A}}}\right)^{1 / 2} \frac{r_{\mathrm{e}}}{x}$

in which, $C_{3}$ is reported to be 15.2 by Lawn [39].

The local critical velocity at blowout can be assumed as a centerline velocity at a corresponding critical axial location just at flame extinction (blowout), which is reasonably taken as the corresponding critical flame length $\left(l_{f}\right)$ (note that the self-similarity scaling of the axisymmetric turbulent jet requires this critical axial location just simply scaled linearly with the critical flame length) $[12,42]$, a value can be determined by increasing the coflow velocity until a blowout occurs.

Then the local flow velocity at blowout becomes:

$U_{\mathrm{L}}=C_{3}\left(U_{\mathrm{F}}-U_{\mathrm{A}}\right)\left(\frac{\rho_{\mathrm{F}}}{\rho_{\mathrm{A}}}\right)^{1 / 2} \frac{r_{\mathrm{e}}}{l_{f}}+U_{\mathrm{A}}$ 
Substituting Eqs. (2) and (5) into Eq. (1) leads to

$$
U_{\mathrm{F}}=\frac{C_{1} C_{2}(1+A F)\left(\rho_{\mathrm{F}} / \rho_{\mathrm{A}}\right)^{1 / 2} d_{\mathrm{F}} S_{\mathrm{L}}^{2} /(\alpha \mathrm{Da})}{\frac{C_{3} /\left(C_{1} C_{2}\right)}{1+A F}\left(1-U^{*}\right)\left[1+\frac{\rho_{\mathrm{A}}\left(d_{\mathrm{A}}^{2}-d_{\mathrm{F}}^{2}\right)}{\rho_{\mathrm{F}} d_{\mathrm{F}}^{2}} U^{* 2}\right]+\left[1+\frac{\rho_{\mathrm{A}}\left(d_{\mathrm{A}}^{2}-d_{\mathrm{F}}^{2}\right)}{\rho_{\mathrm{F}} d_{\mathrm{F}}^{2}} U^{* 2}\right]^{1 / 2}}
$$

where $U^{*}=U_{\mathrm{A}} / U_{\mathrm{F}}$. The critical Da is chosen as 5.6 based on [3] and $A F$ is 15.7 (propane).

In normal gravity, buoyancy can play a significant role. The fuel jet can be accelerated by buoyancy. Buoyancy-induced velocity can be approximated by [43]:

$U_{\mathrm{B}} \sim \sqrt{g_{f}}$

Roper [44] determined the effective velocity of the fuel jet considering the buoyancy effect as

$U_{\mathrm{F}, \mathrm{eff}}=\sqrt{U_{\mathrm{F}, 0}^{2}+2 \zeta l_{f}}$

where $\zeta=g\left(T_{f} / T_{\mathrm{A}}-1\right) \cong 40 \mathrm{~m} / \mathrm{s}^{2}$ and $U_{\mathrm{F}, 0}$ is the fuel jet velocity without considering the buoyancy effect. This estimation is introduced into Eqs. (2) and (6) to account for the gravity (buoyancy) effect.

Figure 9 shows the critical flame length at blow out of the present work (propane) for both normal gravity and microgravity along with the data of Feikema et al. [12] (methane) in normal gravity. The buoyancy effect is taken into account with Eq. (8) for the normal gravity data. The result clearly demonstrates a uniform correlation covering the normal- and micro-gravity conditions when considering the gravity effect in $U_{\mathrm{F}, \text { eff }}$. And the empirical constant $C_{2}$ can be determined from the correlation as 9.6 from the best fit:

$$
\frac{l_{f}}{(1+A F)\left(\rho_{\mathrm{F}} / \rho_{\mathrm{A}}\right)^{1 / 2} d_{\mathrm{F}}}=\frac{9.6}{\left[1+\frac{\rho_{\mathrm{A}} U_{\mathrm{A}}^{2}\left(d_{\mathrm{A}}^{2}-d_{\mathrm{F}}^{2}\right)}{\rho_{\mathrm{F}} U_{\mathrm{F}, \mathrm{eff}}^{2} d_{\mathrm{F}}^{2}}\right]^{1 / 2}}
$$

Now, a non-dimensional velocity $\tilde{U}$ is introduced as the denominator of Eq. (6):

$$
\begin{aligned}
\tilde{U} & =\frac{C_{3} /\left(C_{1} C_{2}\right)}{1+A F}\left(1-U_{\mathrm{eff}}^{*}\right)\left[1+\frac{\rho_{\mathrm{A}}\left(d_{\mathrm{A}}^{2}-d_{\mathrm{F}}^{2}\right)}{\rho_{\mathrm{F}} d_{\mathrm{F}}^{2}} U_{\mathrm{eff}}^{* 2}\right] \\
& +\left[1+\frac{\rho_{\mathrm{A}}\left(d_{\mathrm{A}}^{2}-d_{\mathrm{F}}^{2}\right)}{\rho_{\mathrm{F}} d_{\mathrm{F}}^{2}} U_{\mathrm{eff}}^{* 2}\right]^{1 / 2}
\end{aligned}
$$

in which, $U^{*}$ in Eq. (6) was replaced by $U_{\mathrm{eff}}^{*}=U_{\mathrm{A}} / U_{\mathrm{F}, \text { eff }}$ to take the buoyancy effect into consideration. Then, a global model considering both the coflow velocity effect and the buoyancy effect between micro- and normal gravities can be deduced as:

$U_{F}=\frac{C_{1} C_{2}(1+A F)\left(\rho_{\mathrm{F}} / \rho_{\mathrm{A}}\right)^{1 / 2} d_{\mathrm{F}} S_{\mathrm{L}}^{2}}{\alpha \operatorname{Da} \tilde{U}}$

With regard to the coflow air velocity, substituting Eqs. (11) and (9) into Eq. (8), and then combined with $U_{\text {eff }}^{*}$ leads to

$U_{\mathrm{A}}=U_{\text {eff }}^{*} \sqrt{\left[\frac{C_{1} C_{2}(1+A F)\left(\rho_{\mathrm{F}} / \rho_{\mathrm{A}}\right)^{1 / 2} d_{\mathrm{F}} S_{\mathrm{L}}^{2}}{\alpha \mathrm{Da} \tilde{U}}\right]^{2}+\frac{2 C_{2} \zeta(1+A F)\left(\rho_{\mathrm{F}} / \rho_{\mathrm{A}}\right)^{1 / 2} d_{\mathrm{F}}}{\left[1+\rho_{\mathrm{A}}\left(d_{\mathrm{A}}^{2}-d_{\mathrm{F}}^{2}\right) /\left(\rho_{\mathrm{F}} d_{\mathrm{F}}^{2}\right) U_{\text {eff }}^{* 2}\right]^{1 / 2}}}$

The calculated fuel jet velocity $U_{\mathrm{F}, \mathrm{cal}}$ at blowout using Eq. (11) and coflow air velocity $U_{\mathrm{A} \text {,cal }}$ using Eq. (12) (horizontal axis) are compared with the experimental data (vertical axis) in Fig. 10(a) and (b), respectively. Both the experimental data of the present work and those referred from previous works [10,12,13] are included. The results reveal an overall agreement between the predictions
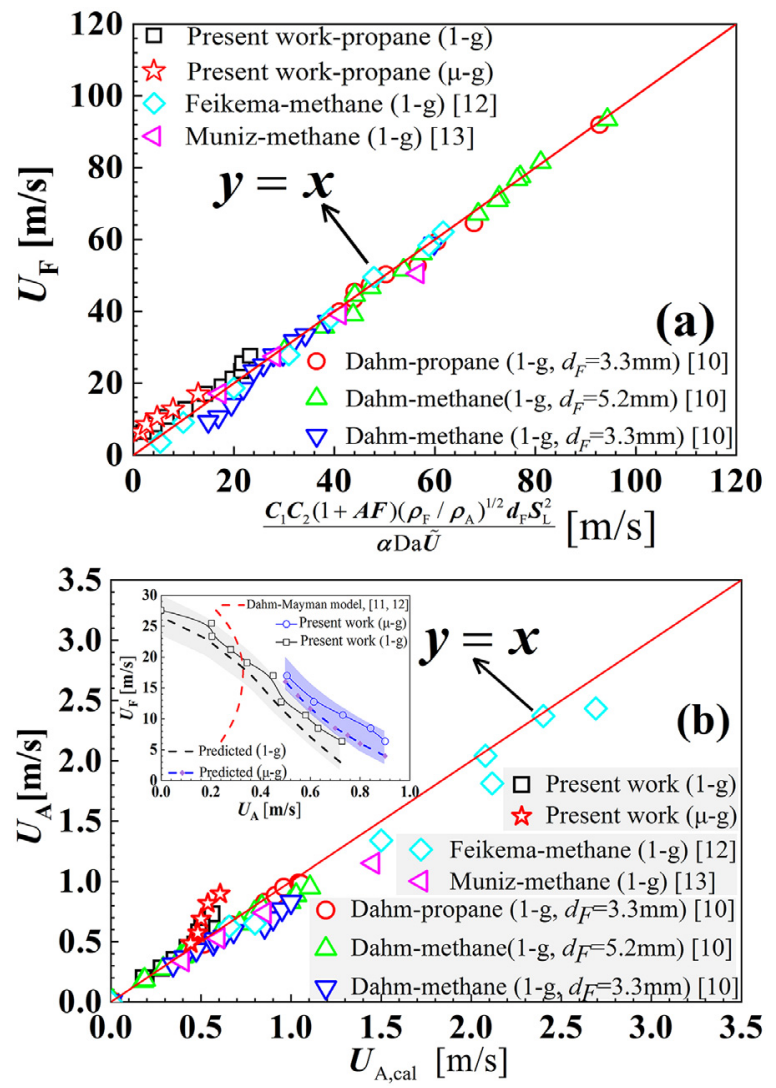

Fig. 10. Comparison of experimental (vertical axis) and calculated (horizontal axis) blowout conditions for (a) fuel jet velocity and (b) coflow air velocity from Eqs. (11) and (12), respectively.

and experiments, suggesting that Eqs. (11) and (12) are reliable in predicting the blowout limit for turbulent non-premixed jet flames accounting for both the effects of coflow and buoyancy in normaland micro-gravities. It should also be noted that there is some deviation of the model prediction with the present experimental results on blowout coflow velocity as shown in Fig. 10(b). To show this more clearly, a more direct comparison similar to Fig. 8 is presented, as an inset-figure in Fig. 10(b). It shows that the model can have a much better prediction than that of Dahm's model [11,12] and a good reflection on the difference between normal gravity and microgravity, as well as the variation trend. However, the prediction is still slightly lower than the experimental data in both gravity levels. A possible reason could be attributed to the selection of the value of jet spreading rate constant, $C_{1}$, which was reported [45-50] to vary from $0.168-0.256$ due to the variation of density ratio of fuel and ambient environment [47] and turbulence intensity [50]. The model prediction range with different values of jet spreading rate constant $C_{1}$ referred from previous works [45-50] is quantified in the inset-figure in Fig. 10(b), showing that the experimental results can be included within the range (shadow region). It would be valuable to further examine the effect of value of jet spreading rate constant $C_{1}$ in the future. Meanwhile, experiments with various fuels (for example, higher hydrocarbonnumber fuels) and diluted conditions (Lewis number effect) which influences laminar flame speed, as well as with higher flow velocities and larger size nozzles will be also a potential future work to validate the developed model in the present study.

\section{Conclusions}

This paper investigates the flame blowout behavior in nonpremixed turbulent jet flames with coflow in microgravity, and 
compared with that obtained in normal gravity. Major findings include:

(1) The flame length in microgravity is observed to be longer than that in normal gravity, and decreases with increasing coflow air velocity. The flame in microgravity shows more intense yellow luminosity with larger sooting zone.

(2) The flame liftoff height increases with increasing coflow air velocity in both gravity levels, and the flame base are stabilized closer to the burner in microgravity as compared with that in normal gravity.

(3) The blowout limit in microgravity is significantly larger than that obtained in normal gravity. A physical model based on the Damköhler ( $\mathrm{Da})$ number is developed to characterize the difference in the blowout limits in micro- and normalgravities by taking into account the buoyancy effect. The effect of coflow velocity is also incorporated and the proposed model can successfully predict the blowout limits.

The findings obtained in the present study provide new data and basic scaling analysis for blowout limit of non-premixed turbulent jet flames considering both the coflow and buoyancy effects.

\section{Acknowledgments}

This work was supported jointly by National Natural Science Foundation of China (NSFC) (51976051, 51636008, 51606057, and U1738117) and Key Research Program of Frontier Sciences, Chinese Academy of Science (CAS) under Grant No. QYZDB-SSWJSC029. OF was supported by a Grand-in-Aid for Scientific Research (KIBAN(A) No. 18H03755). SHC was supported by King Abdullah University of Science and Technology (KAUST). This work was also supported by Fundamental Research Funds for the Central Universities (JZ2018HGTB0256), China Postdoctoral Science Foundation funded project (2018T110625; 2016M590580), and the Strategic Pioneer Program on Space Science, the Chinese Academy of Sciences under Grant No. XDA15012800.

\section{References}

[1] L. Vanquickenborne, A. van Tiggelen, The stabilization mechanism of lifted diffusion flames, Combust. Flame 10 (1) (1966) 59-69.

[2] G.T. Kalghatgi, Blow-out stability of gaseous jet diffusion flames. Part I: in still air, Combust. Sci. Technol. 26 (5-6) (1981) 233-239.

[3] J.E. Broadwell, W.J.A. Dahm, M.G. Mungal, Blowout of turbulent diffusion flames, Symp. (Int.) Combust. 20 (1985) 303-310.

[4] Y.M. Annushkin, E.D. Sverdlov, Stability of submerged diffusion flames in subsonic and underexpanded supersonic gas-fuel streams, Combust. Explor. Shock Waves 14 (1979) 597-605.

[5] C.Y. Wu, Y.C. Chao, T.S. Cheng, Y.H. Li, K.Y. Lee, T. Yuan, The blowout mechanism of turbulent jet diffusion flames, Combust. Flame 145 (2006) 481-494.

[6] S.H. Chung, B.J. Lee, On the characteristics of laminar lifted flames in a nonpremixed jet, Combust. Flame 86 (1991) 62-72.

[7] B.J. Lee, S.H. Chung, Stabilization of lifted tribrachial flames in a laminar nonpremixed jet, Combust. Flame 109 (1997) 163-172.

[8] B.J. Lee, J.S. Kim, S.H. Chung, Effect of dilution on the liftoff of non-premixed jet flames, Symp. (Int.) Combust. 25 (1994) 1175-1181.

[9] J. Lee, S.H. Won, S.H. Jin, S.H. Chung, Lifted flames in laminar jets of propane in coflow air, Combust. Flame 135 (2003) 449-462.

[10] W.J.A. Dahm, R.W. Dibble, Coflowing turbulent jet diffusion flame blowout, Symp. (Int.) Combust. 22 (1988) 801-808.

[11] W.J.A. Dahm, A.G. Mayman, Blowout limits of turbulent jet diffusion flames for arbitrary source conditions, AIAA J. 28 (1990) 1157-1162.

[12] D. Feikema, R.H. Chen, J.F. Driscoll, Blowout of nonpremixed flames maximum coaxial air, Combust. Flame 86 (1991) 347-358.

[13] L. Muniz, M.G. Mungal, Instantaneous flame-stabilization velocities in lifted-jet diffusion flames, Combust. Flame 111 (1997) 16-31.

[14] C.D. Brown, K.A. Watson, K.M. Lyons, Studies on lifted jet flames in coflow the stabilization mechanism in the near- and far-fields, Flow Turbul. Combust. 62 (1999) 249-273.

[15] A.J. Lock, A.M. Briones, X. Oin, S.K. Aggarwal, I.K. Puri, U. Hegde, Liftoff characteristics of partially premixed flames under normal and microgravity conditions, Combust. Flame 143 (2005) 159-173.
[16] Y. Bahadori, J.F. Small Jr., U.G. Hegde, L. Hou, D.P. Stocker, Characteristics of transitional and turbulent jet diffusion flames in microgravity, NASA Conference Publication (1995), pp. 327-332. 10174.

[17] J.E. Brooker, K. Jia, D.P. Stocker, L.D. Chen, Influence of Buoyant Convection on the Stability of Enclosed Laminar Flames, Fourth United States Microgravity Payload, One Year Report, 1997, p. 151.

[18] G.T. Tang, H. Zhang, M.M. Zhu, H. Yang, G.X. Yue, S. Wang, X. Wan, Experimental study on the ignition process of single coal particles at microgravity, Microgravity Sci. Technol. 22 (2010) 27-35.

[19] H. Zhang, R. Fan, S. Wang, X. Tian, K. Xu, S. Wan, F.N. Egolfopoulos, Extinction of lean near-limit methane air flames at elevated pressures under normal- and reduced-gravity, Proc. Combust. Inst. 33 (2011) 1171-1178.

[20] N. Otsu, A threshold selection method from gray-level histograms, IEEE Trans. Syst. Man Cybern. B 9 (1979) 62-66.

[21] Q. Wang, L.H. Hu, M. Zhang, F. Tang, X.C. Zhang, S.X. Lu, Lift-off of jet diffusion flame in sub-atmospheric pressures: an experimental investigation and interpretation based on laminar flame speed, Combust. Flame 161 (2014) 1125-1130.

[22] L.H. Hu, Q. Wang, M. Delichatsios, F. Tang, X.C. Zhang, S.X. Lu, Flame height and lift-off of turbulent buoyant jet diffusion flames in a reduced pressure atmosphere, Fuel 109 (2013) 234-240.

[23] J.M. Most, P. Mandin, J. Chen, P. Joulain, D. Durox, A.C. Fernande-Pello, Influence of gravity and pressure on pool fire-type diffusion flames, Symp. (Int.) Combust. 26 (1996) 1311-1317.

[24] M.R. Charest, C.P. Groth, Ö.L. Gülder, A numerical study on the effects of pressure and gravity in laminar ethylene diffusion flames, Combust. Flame 158 (2011) 1933-1945.

[25] C.R. Kaplan, E.S. Oran, K. Kailasanath, H.D. Ross, Gravitational effects on sooting diffusion flames, Symp. (Int.) Combust. 26 (1996) 1301-1309.

[26] Y.M. Bahadori, J.F. Small Jr, U.G. Hegde, L. Zhou, D.P. Stocker, Characteristics of transitional and turbulent jet diffusion flames in microgravity, 1995.

[27] D.L. Dietrich, H.D. Ross, D.T. Frate, J.S. T'ien, Y. Shu, Candle flames in microgravity, 4th International Microgravity Combustion Workshop (NASA Conference Publication 10194) (1997), pp. 237-242.

[28] https://www.nasa.gov/sites/default/files/atoms/files/np-2015-10-034jsc combustion_in_reduced_gravity-iss-mini-book-011116-508.pdf.

[29] https://science.nasa.gov/science-news/science-at-nasa/2013/18jun_ strangeflames.

[30] W.F. Du, X.Q. Zhang, G.M. Wei, Y. Hua, W.J. Kong, The candle flame in microgravity, J. Eng. Thermophys. 21 (2000) 515-519.

[31] D.L. Urban, Z.G. Yuan, P.B. Sunderland, G.T. Linteris, J.E. Voss, K.C. Lin, G.M. Faeth, Structure and soot properties of nonbuoyant ethylene/air laminar jet diffusion flames, AIAA J. 36 (1998) 1346-1360.

[32] S.H. Chung, Stabilization, propagation and instability of tribrachial triple flames, Proc. Combust. Inst. 31 (2007) 877-892.

[33] A.J. Lock, A.M. Briones, X. Qin, S.K. Aggarwal, I.K. Puri, U. Hegde, Liftoff characteristics of partially premixed flames under normal and microgravity conditions, Combust. Flame 143 (2005) 159-173.

[34] K.T. Walsh, Quantitative Characterizations of Coflow Laminar Diffusion Flames in a Normal Gravity and Microgravity Environment, Yale University, 2000.

[35] M.R.J. Charest, P.T.G. Clinton, Ö.L. Gülder, A numerical study on the effects of pressure and gravity in laminar ethylene diffusion flames, Combust. Flame 158 (2011) 1933-1945.

[36] J. Kim, K.N. Kim, S.H. Won, O. Fujita, J. Takahashi, S.H. Chung, Numerical simulation and flight experiment on oscillating lifted flames in coflow jets with gravity level variation, Combust. Flame 145 (2006) 181-193.

[37] H.G. Darabkhani, Q. Wang, L. Chen, Y. Zhang, Impact of co-flow air on buoyant diffusion flames flicker, Energy Convers. Manag. 52 (2011) 2996-3003.

[38] M.S. Cha, S.H. Chung, Characteristics of lifted flames in nonpremixed turbulent confined jets, Proc. Combust. Inst. 26 (1996) 121-128.

[39] C.J. Lawn, Lifted flames on fuel jets in co-flowing air, Prog. Energy Combust. Sci. 35 (2009) 1-30.

[40] W.J.A. Dahm, Effects of heat release on turbulent shear flows: part 2. Turbulent mixing layers and the equivalence principle, J. Fluid Mech. 540 (2005) 119.

[41] M. Kim, J. Oh, Y. Yoon, Flame length scaling in a non-premixed turbulent diluted hydrogen jet with coaxial air, Fuel 90 (2011) 2624-2629.

[42] W.J.A. Dahm, A.G. Maymant, Blowout limits of turbulent jet diffusion flames for arbitrary source conditions, AIAA J. 28 (1990) 1157-1165.

[43] C.A. Idicheria, I.G. Boxx, N.T. Clemens, Characteristics of turbulent nonpremixed jet flames under normal- and low-gravity conditions, Combust. Flame 138 (2004) 384-400.

[44] F.G. Roper, The prediction of laminar jet diffusion flame sizes: part I. Theoretical model, Combust. Flame 29 (1977) 219-226.

[45] G. Brown, A. Roshko, On density effects and large structure in turbulent mixing layers, J. Fluid Mech. 64 (1974) 775-816.

[46] A. Roy, C. Segal, C. Joly, Spreading angle and core length analysis of supercritical jets, AIAA J. 51 (2013) 2009-2014.

[47] P.C.K. Chu, J.H. Lee, V.H. Chu, Spreading of turbulent round jet in coflow, J. Hydr. Eng. 125 (1999) 193-204

[48] M.H. Gazzah, N. Boughattas, H. Belmabrouk, R. Said, The dynamic field in turbulent round jet discharging into a co-flowing stream, Nat. Sci. 2 (2010) 635.

[49] N.E. Kotsovinos, A note on the spreading rate and virtual origin of a plane turbulent jet, J. Fluid Mech. 77 (1976) 305-311.

[50] S.R. Turns, An Introduction to Combustion, McGraw-hill, New York, 1996 